\title{
Changes of Children's Motivation in Physical Education and Physical Activity: A Longitudinal Perspective
}

\author{
Xiangli Gu, Tao Zhang \\ The Department of Kinesiology, Health Promotion, and Recreation, University of North Texas, Denton, USA \\ Email: xiangli.gu@unt.edu
}

Received 8 July 2016; accepted 5 August 2016; published 8 August 2016

Copyright (C) 2016 by authors and Scientific Research Publishing Inc.

This work is licensed under the Creative Commons Attribution International License (CC BY). http://creativecommons.org/licenses/by/4.0/

(c) (i) Open Access

\begin{abstract}
Children's motivation towards Physical Education (PE) decreases over the elementary school year, but little is known about how and why those declines influence changes of children's intention and Physical Activity (PA). Guided by the expectancy-value model, this study attempted to examine the relationship between changes of children's motivation to changes in children's intention for future participation in PE and PA over an academic year. Using a repeated measurement technique, 354 $\left(4^{\text {th }} 180,5^{\text {th }} 174\right)$ school children's expectancy-related beliefs, task values, intention, and PA were assessed twice over one academic school year. Time 1 was at the beginning of the fall semester, and Time 2 was at the end of the subsequent spring semester. Students' expectancy-related beliefs and task values were positively related to their intention and PA at both Time 1 and Time 2 . A factorial repeated measure MANOVA showed that decreases in task values and intention were significant $(p<.01)$. Regression analyses indicated that decreases in children's expectancy-related beliefs and task values explained significant variance in a decrease in their intention. Additionally, changes of expectancy-related beliefs emerged as significant predictors of changes in children's PA. The findings revealed that children perceived less values toward PE across one academic year. Consequently, this change could contribute to the decreases in children's intention for future participation. Thus, PE teachers should focus on learning activities students perceive as important, interesting, and usefulness in elementary school.
\end{abstract}

\section{Keywords}

Motivation, Physical Activity Change, School Children, Physical Education

\section{Introduction}

In the physical education literature, many studies have demonstrated that the strength and quality of students' 
motivated behaviors, such as persistence, intention, and physical activity, are closely linked to their beliefs about one's ability and subjective values in the context of physical education (Eccles et al., 1983; Gao, Lee, Solmon, \& Zhang, 2009; Gu \& Solmon, 2016; Xiang, McBride, \& Bruene, 2006). To understand students’ achievement motivation and motivated behaviors, Eccles and her colleagues developed the expectancy-value model of achievement choice (Eccles et al., 1983; Eccles, Wigfield, \& Schiefele, 1998). They proposed two primary determinants of achievement behaviors: (a) the individual's expectancy-related beliefs, consisting of beliefs about ability and expectancies for success in a particular domain; and (b) the subjective values associated with the task. According to the expectancy-value model of achievement choice, belief about ability and expectancy for success comprise the two major components of expectancy-related beliefs. These components are related to each other although they are conceptually distinct. Subjective task values are defined as an incentive, that is, how an achievement task meets various needs of individuals. The main components of the task values include attainment value (importance), intrinsic value (interest), and utility value (usefulness) (Eccles et al., 1983; Eccles, Wigfield, \& Schiefele, 1998). Researchers have suggested that students tend to engage and participate in activities in which they believe they are competent, as well as those that they view as interesting, important, and useful in school physical education domains (Eccles et al., 1983; Gao et al., 2009; Gu \& Solmon, 2016; Wigfield \& Eccles, 2002; Zhang, Solmon, \& Gu, 2012).

In order to optimize the application of the expectancy-value model, it is important to consider how children's expectancy-related beliefs and subjective task values evolve as they progress through school. According to the expectancy-value model, children's expectancy-related beliefs and subjective task values together enable them to differentiate and evaluate their ability and activity values. If children can identify what they are good at and what they value, the expectancy value information is more likely to be used in decision making. In considering the development of children's expectancy-related beliefs and subjective task values, one main approach has been used to explore changes in mean levels of expectancies and values over time in school. Most studies have reported that children's expectancy-related beliefs decline across school years in sport and physical education (Caspersen, Pereira, \& Curran, 2000; Gao, Lee, \& Harrison, 2008; Jacobs, Lanza, Osgood, Eccles, \& Wigfield, 2002; Xiang et al., 2006; Xiang, McBride, Guan, \& Solmon, 2003). For example, Jacobs and her colleagues in their longitudinal study found children's expectancy-related beliefs in sport declined over the course of schooling and that this decline accelerated over time from $1^{\text {st }}$ through $12^{\text {th }}$ grade (Jacobs et al., 2002). Xiang and her colleagues reported there was a decline occurring in the transition from primary to intermediate grades in children's expectancy-related beliefs in physical education (Xiang et al., 2003). These results demonstrate that the decline of physical education-related motivation and competence beliefs in physical activity evident in schoolaged children begins in elementary school (Jacobs et al., 2002; Xiang et al., 2003).

With regard to the expectancy-related beliefs, researchers examining changes in the mean level of children's values generally have found that older children's overall ratings of task values (i.e., importance, interest, and usefulness) for sport and physical education decrease compared with younger children (Jacobs et al., 2002; Wigfield \& Eccles, 2002; Xiang et al., 2006; Xiang et al., 2003). In the Fredricks and Eccles’ longitudinal study, they found that the ratings of interest declined slightly, and a larger decline in the perceptions of importance of sports (Fredricks \& Eccles, 2002). In addition, Wigfield and colleagues also indicated that there were decreases in the perceptions of the usefulness and importance of sports, whereas the interest in sport remained stable over a three-year period (Wigfield et al., 1997). Researchers extended the finding in the physical education setting that younger children reported higher subjective task values than older children, but the significant decreases of the subjective task values only observed in the younger group ( $2^{\text {nd }}-3^{\text {rd }}$ grades) (Xiang et al., 2006). Based on this evidence, further study is needed to understand children's changes of subjective task values toward physical education across school years and to develop strategies to prevent this decline.

Taken together, students' motivation to participate in physical education programs declines as they grow older, and the decline has been observed as early as second grade (Eccles, Wigfield, Harold, \& Blumenfeld, 1993; Fredricks \& Eccles, 2002; Gao et al., 2009; Jacobs et al., 2002; Xiang et al., 2006). Consistent with the expectancy-value model, Xiang and colleagues provided initial evidence that the decreases of expectancy-related beliefs and subjective task values may be related to a decrease in the intention for future participation in physical education among second and third graders (Xiang et al., 2006). Recent research has shown that students' overall physical activity participation is associated with intention and motivation-related experiences in physical education (Cox, Smith, \& Williams, 2008; Gu \& Solmon, 2016). For example, Gu and Solmon (2016) provided the cross-sectional evidence that motived (i.e., higher expectancy-value beliefs) elementary students are more active 
during after school period, and more likely to participate in physical education in the future. However, those students' actual physical activity participation during physical education was lower than their counterparts' physical activity. The reasons for these inconsistent findings remain unclear.

Improving physical activity participation and health are identified as major outcomes for school physical education and are also major goals of Healthy People 2020 (SHAPE America, 2014; USDHHS, 2010). Research indicated motivational processes in physical education can impact students' intention for future participation, and physical activity both within and outside of physical education (Gu \& Solmon, 2016). Questions are still unanswered in the physical education literature, however, such as "how do changes in motivation student experiences in physical education correspond to their physical activity participation?" and "are the declines in the motivation in physical education significantly correlated to the changes of physical activity from developmental perspective?”.Guided by the expectancy-value model, the major purpose of this study was to examine the developmental trend of students' expectancy-values beliefs, task values, intention for future participation in physical education, and physical activity across one academic school year. The second purpose was to investigate the relationship between changes of students' motivation (expectancy-value beliefs) and changes in students' intention for future participation and physical activity over an academic year while controlling for students' motivation and physical activity from the previous semester.

\section{Methods}

\subsection{Participants}

Participants were 354 (168 boys, 186 girls) elementary school students recruited from three public schools in the southeastern United States. The participants consisted of fourth and fifth graders $\left(4^{\text {th }} 180 ; 5^{\text {th }} 174\right)$ ranging in age from 9 - 13 years $(\mathrm{M}$ age $=9.9$, SD = .7). The majority of the participants $(53.4 \%)$ were White students and the remainder (46.6\%) included African-American (37.9\%), Asian-American (1.4\%), Hispanic-American (1.7\%) and others (5.6\%). Approval to conduct the study was received from the University Institutional Review Board. Permission to collect data in the schools was granted by the school district, the school principal, and the physical educators before the start of the study. Informed parental consent and child assent forms were obtained from participants in accordance with the University Institutional Review Board and school district requirements.

\subsection{Measures}

Demographic information included the students' grade, gender, race, school, and age. Standardized self-report questionnaires were used to assess students' expectancy-value beliefs, subjective task values, intention for future participation in physical education, and overall physical activity (PAQ-C) at fall (Time 1) and spring (Time 2) semesters, respectively.

Expectancy-related beliefs: The participants were asked five questions to assess their expectancy-related beliefs toward physical education class using a 5-point Likert scale (Xiang et al., 2006). The example questions include (a) How good are you at activities and games in physical education? ( 1 = very bad, 5 = very good); (b) How good are you at activities and games in physical education, compared to most of your other school subjects? ( 1 = a lot worse in this activity, 5 = a lot better in this activity); and (c) How good would you be at learning something new in physical education this year? $(1=$ very bad, $5=$ very good $)$. The mean of these five items provides an overall indication of the magnitude of a student's expectancy-related beliefs. The internal consistency reliability of this scale obtained in this study and reported in Table 1.

Subjective task values: A 6-item validated instrument was used to assess the participants' subjective task values (Xiang et al., 2006). Example items of the scale include: (a) For me, being good at activities and games in physical education is... ( 1 = Not very important, 5 = Very important); (b) How much do you like activities and games in physical education? ( 1 = Don't like it at all, 5 = Like it very much); and (c) Compared to your other school subjects, how useful is what you learn in physical education? $(1=$ Not useful at all, 5 = Very useful). Participants were asked to respond on each item with a 5-point scale. The mean of these six items was used as students' subjective task values (alpha coefficients were reported in Table 1).

Intention for future participation in physical education: The students were asked to respond to a single question on a 5-point scale: "When you get to high school, you will have a choice whether you want to take physical education. How much would you want to take it?” ( 1 = not at all, 5 = very much). Previous research provided 
Table 1. Correlations among the study variables $(\mathrm{N}=354)$.

\begin{tabular}{|c|c|c|c|c|c|c|c|c|}
\hline Measure & 1 & 2 & 3 & 4 & 5 & 6 & 7 & 8 \\
\hline 1. Expectancy beliefs-1 & $(.72)$ & & & & & & & \\
\hline 2. Task values-1 & $.58^{* *}$ & (.73) & & & & & & \\
\hline 3. Intention-1 & $.53^{* *}$ & $.48^{* *}$ & - & & & & & \\
\hline 4. Physical activity-1 & $.30^{* *}$ & $.26^{* *}$ & $.23^{* *}$ & $(.87)$ & & & & \\
\hline 5. Expectancy beliefs-2 & $.46^{* *}$ & $.30^{* *}$ & $.45^{* *}$ & $.33^{* *}$ & $(.70)$ & & & \\
\hline 6. Task values-2 & $.20^{* *}$ & $.30^{* *}$ & $.30^{* *}$ & $.13^{*}$ & $.46^{* *}$ & $(.80)$ & & \\
\hline 7. Intention-2 & $.26^{* *}$ & $.23^{* *}$ & $.49^{* *}$ & $.27^{* *}$ & $.46^{* *}$ & $.47^{* *}$ & - & \\
\hline 8. Physical activity-2 & $.27^{* *}$ & $.20^{* *}$ & $.28^{* *}$ & $.43^{* *}$ & $.39^{* *}$ & $.23^{* *}$ & $.27^{* *}$ & $(.86)$ \\
\hline$M$ & 4.22 & 4.16 & 4.36 & 3.34 & 4.17 & 3.96 & 4.17 & 3.31 \\
\hline$S D$ & .71 & .71 & .86 & .86 & .54 & .68 & .95 & .61 \\
\hline
\end{tabular}

Note. Cronbach alpha coefficients for self-reported measures at Time 1 and Time 2 are provided along the diagonal; $M=M e a n, S D=S t a n d a r d ~ D e v i-$ ation; ${ }^{*} p<.05 .{ }^{* *} p<.01$

evidence for the reliability and validity of this intention measure with elementary children in both academic and physical education settings (Gu \& Solmon, 2015; Xiang et al., 2003).

Physical activity: The Physical Activity Questionnaire for Older Children (PAQ-C) was used to assess students' overall physical activity (Kowalski, Crocker, \& Faulkner, 1997). The PAQ-C is a 7-day recall questionnaire intended to assess students' moderate-to-vigorous physical activity (MVPA) in specific physical activities as well as general physical activity levels during different times of the day/week (Kowalski, Crocker, \& Faulkner, 1997). Other physical activity behaviors related to students' physical education class, free time, recess, extracurricular sports, weekend activities, and evening activities are also addressed with the PAQ-C. One item, "In the last 7 days, during your physical education classes, how often were you very active (playing hard, running, jumping, throwing)?” represented MVPA during physical education. A final overall score was obtained as an indicator of physical activity level for each student (alpha coefficients were reported in Table 1) (Kowalski, Crocker, \& Faulkner, 1997).

\subsection{Research Design and Procedures}

A repeated measurement technique was used to analyze students' self-reported survey data collected in two time waves across an academic school year. Time 1 was at the beginning of the fall semester, and Time 2 was at the end of the subsequent spring semester. All questionnaires were administered and collected in classrooms in groups of 25 to 30 students. These questionnaires were distributed to all students under the supervision of the researchers. In order to ensure that students understood the items and read each item carefully, trained research assistants read each item of the instrument to the students and answered questions when clarification was needed. Students spent approximately 15 - 20 minutes completing all questionnaires.

\subsection{Data Analyses}

All statistical analyses were conducted using SPSS (version 22.0). First, Cronbach's alpha coefficients were used to examine the internal consistencies of the self-reported measures. Pearson product-moment correlations and descriptive statistics were calculated for all variables at Time 1 and Time 2. Second, A 2 (Time 1 and Time 2 measures) $\times 2$ (boys and girls) $\times 2\left(4^{\text {th }}\right.$ and $\left.5^{\text {th }}\right)$ factorial repeated measures MANOVA was used to examine mean level changes in students' expectancy-value beliefs, task values, intention for future participation in physical education, and physical activity, with time as a within-subjects factor and gender and grade as between-subjects factors. Follow-up univariate tests were conducted when the MANOVA yielded main effects for gender, grade, and time. Post hoc tests were adjusted for multiple comparisons using the Bonferroni adjustment.

Finally, a series of hierarchical regression analyses were performed to test if the changes of expectancy-related beliefs and task values over time predicted changes in intention for future participation and physical activity. The 
following procedure was used for each dependent variable. Specifically, for the physical activity (dependent variable) model, the corresponding Time 1 scores (independent variables) including expectancy-related beliefs, task values and physical activity was entered first (step 1); expectancy-related beliefs and task values at Time 2 were entered second (step 2). For the intention for future participation (dependent variable) model, the procedure was the same as physical activity model, exception the Time 1 intention score was controlled in the first step. An alpha level of .05 was used for all the data analyses.

\section{Results}

The descriptive statistics of all variables in both times are shown in Table 1. Students' expectancy-related beliefs and task values were positively related to their intention for future participation and physical activity at both Time 1 and Time 2. Alpha coefficients for all scales at both Time 1 and Time 2 were acceptable ranging from .70 to .87 (Table 1 ).

The results of the MANOVA demonstrated that there were significant effects for within-subjects differences (Time 1 and Time 2 measures; Wilks' Lambda $=.91, F(4,346)=8.59, p<.001, \eta^{2}=.09$ ), without any significant interactions among time, gender, and grade $(p>.05)$. Additionally, there were main significant betweensubjects differences for gender (Wilks' Lambda $=.882, F(4,346)=11.61, p<.001, \eta^{2}=.12$ ) and grades (Wilks' Lambda $\left.=.929, F(4,346)=6.64, p<.001, \eta^{2}=.07\right)$, but no gender by grades interaction. Univariate test showed that $4^{\text {th }}$ grade children reported higher task values, intention for future participation, and physical activity $(p<.01)$. Boys had higher expectancy beliefs, intention and physical activity compared to their counterparts $(p<.001)$. Post hoc analyses showed that all study variables decreased from Time 1 to Time 2, but decreases in task values and intention reached the statistically significant level $(p<.001$; Table 2$)$.

The examination of linear relationship among the independent variables suggested that the assumption of no multicollinearity was met; the VIF and Tolerance statistics for the independent variables involved were all less than 5 and greater than .20, respectively. Results from the hierarchical regression analyses (shown in Table 3) showed that children's expectancy-related beliefs $(\beta=.20, p<.001)$ and task values $(\beta=.31, p<.001)$ explained significant variance (Total $R^{2}=.39$ ) in their intention for future participation after controlling for the Time 1 scores of the variables in the model. Furthermore, the results also indicated that changes of expectancy-related beliefs but not task values emerged as significant predictors of changes in children's physical activity using the same method as before (Total $R^{2}=.26, \beta=.21, p<.001$ ). The hierarchical structure indicates how changes in expectancy-value beliefs are related to changes in physical activity and intention respectively over one academic year by statistically controlling for the initial levels of each variables. Thus, the coefficients reported for the second step were considered as predicting residual variance in each interested variable, unexplained by the respective variables' initial level.

\section{Discussion}

School physical education programs have been identified as potentially important settings in efforts to increase school-aged students' physical activity levels and therefore, is a primary avenue for helping children learn the skills and knowledge needed to lead healthy and physically active lifestyles (Chen, 2015; SHAPE America, 2014). The expectancy-value model of achievement choice has proven to be a useful framework to understand school children's motivation and motivated behaviors and choices in physical education. Understanding how

Table 2. Results of factorial repeated measure ANOVA for Time 1 and Time 2 ( $\mathrm{N}=354)$.

\begin{tabular}{cccccc}
\hline & Time 1 & Time 2 & \multicolumn{3}{c}{ Contrast within-subjects } \\
\hline & M (SD) & M (SD) & F (1, 349) & $\eta^{2}$ & $p$ \\
\hline Expectancy-related beliefs & $4.23(.68)$ & $4.18(.53)$ & 2.56 & .01 & .111 \\
Task values & $4.17(.68)^{* *}$ & $3.95(.68)^{* *}$ & 26.87 & .07 & .001 \\
Intention & $4.37(.86)^{* *}$ & $4.18(.95)^{* *}$ & 14.84 & .04 & .001 \\
Physical activity & $3.34(.86)$ & $3.31(.61)$ & .74 & .00 & .390 \\
\hline
\end{tabular}

Note. $M=$ Mean, $S D=$ Standard Deviation; ${ }^{* *} p<.01$. 
Table 3. Hierarchical regression analyses for intention and physical activity at Time $2(\mathrm{~N}=354)$.

\begin{tabular}{|c|c|c|c|c|c|c|c|}
\hline Variables & B & SE B & $R^{2}$ & $\beta$ & $p$ & Tolerance & VIF \\
\hline \multicolumn{8}{|l|}{$\begin{array}{l}\text { Intention for future } \\
\text { participation-2 }\end{array}$} \\
\hline Step 1 & & & .24 & & & & \\
\hline Expectancy-beliefs-1 & .02 & .10 & & .02 & .809 & .441 & 2.27 \\
\hline Task value-1 & -.04 & .10 & & -.03 & .648 & .471 & 2.12 \\
\hline Intention-1 & .55 & .06 & & .50 & .001 & .698 & 1.43 \\
\hline Step 2 & & & .39 & & & & \\
\hline Expectancy-beliefs-1 &.- .05 & .10 & & -.03 & .628 & .383 & 2.61 \\
\hline Task value-1 & -.14 & .09 & & -.10 & .126 & .427 & 2.34 \\
\hline Intention-1 & .41 & .06 & & .37 & .001 & .640 & 1.56 \\
\hline Expectancy-beliefs-2 & .35 & .10 & & .20 & .001 & .597 & 1.67 \\
\hline Task values-2 & .43 & .07 & & .31 & .001 & .714 & 1.40 \\
\hline \multicolumn{8}{|l|}{ Physical activity-2 } \\
\hline Step 1 & & & .21 & & & & \\
\hline Expectancy-beliefs-1 & .14 & .06 & & .17 & .021 & .432 & 2.31 \\
\hline Task value-1 & -.02 & .06 & & -.02 & .755 & .443 & 2.26 \\
\hline Physical activity-1 & .27 & .04 & & .39 & .001 & .908 & 1.10 \\
\hline Step 2 & & & .26 & & & & \\
\hline Expectancy-beliefs-1 & .06 & .07 & & .07 & .343 & .364 & 2.75 \\
\hline Task value-1 & -.02 & .06 & & -.03 & .701 & .403 & 2.48 \\
\hline Physical activity-1 & .24 & .04 & & .33 & .001 & .857 & 1.17 \\
\hline Expectancy-beliefs-2 & .24 & .07 & & .21 & .001 & .596 & 1.68 \\
\hline Task value- 2 & .08 & .05 & & $\begin{array}{l}.21 \\
.09\end{array}$ & .101 & .726 & 1.38 \\
\hline
\end{tabular}

Note: $F$-test and adjusted $R^{2}$ were conducted to assess model fit. $R^{2}$ values are cumulative, with each incremental step adding to the variance explained; $\beta$ values are standardized regression coefficients at each step of the regression analysis.

changes of expectancy-value motivation may correlate to changes of physical activity can help physical educators and other practitioners to carefully structure the sport or activity environment to maximize the positive expectancies and values that individuals have for the activity. However, limited attention has been paid to this research initiative, as well as the developmental trend (changes) of children's physical education motivation and physical activity behaviors, especially in the transition period from elementary to middle school years (i.e., $4^{\text {th }}$ and $5^{\text {th }}$ grades).

Physical education researchers have well-established that predictive utilities of expectancy-value beliefs toward physical education-related outcomes such as intention and physical activity participation, whereas, the longitudinal approach in this study helps to extend past research in the expectancy-value literature (Gao et al., 2009; Gu \& Solmon, 2016; Xiang et al., 2006). Specific questions, such as why children become less active and have less intention to participate in physical education across one academic year, were identified as a result of the hierarchical regression analyses. Our results indicated that changes of expectancy-related beliefs emerged as the most important predictor of children's overall physical activity participation after controlling the initial levels of physical activity. Specifically, students tend to engage in and participate in activities in which they believe they are competent across school years. In another word, for those who maintain their perceived competence in physical education, there may be a direct positive impact on their future physical activity participation. This finding suggests that physical educators and health promoters should focus on enhancing students' confidence in physical education which may help with adopting and maintaining physically active lifestyles.

Consistent with earlier research work, both expectancy-related beliefs and task values were related to intention for future participation in physical education (Gu \& Solmon, 2016; Xiang, McBride, \& Bruene, 2006). One of the important implications of this study was to expand the evidence from the longitudinal perspective. It was found that changes in both expectancy-related beliefs and task values toward physical education accounted for significant variance in the model. Thus, physical education teachers should focus on teaching activities students perceive as important, interesting, and useful in elementary school physical education. Specifically, teachers and coaches should emphasize the value of the activity, foster the belief that success will result when effort is expended, and design tasks/activities that meet all level needs (Gu \& Solmon, 2016). 
Cox and colleagues suggested that perceived expectancy-related beliefs were more stable over time than task values in middle school physical education (Cox, Smith, \& Williams, 2008). Although we observed the decreases in the expectancy-related beliefs across one academic year among our elementary sample, the decreases did not reach a statistically significant. The findings were consistent with theoretical-based indication that young children always believe they are competent in the upcoming tasks, and the expectancy-related beliefs become more accurate and realistic as children grow older (Fredricks \& Eccles, 2002; Xiang, McBride, \& Bruene, 2006). Eccles and Harold lamented that gender differences emerged as young as six years old, our findings also provided insight that even though $4^{\text {th }}$ and $5^{\text {th }}$ graders demonstrated a significant decrease of perceived task values toward physical education across one academic year (Eccles \& Harold, 1991). Both $4^{\text {th }}$ and $5^{\text {th }}$ graders tend to perceive physical education as less important, interest, and usefulness even across one academic year and young children perceived more values of physical education compared to older children. Consequently, this decrease significantly contributed to the decrease in their intention for future participation which was reported in our regression models. Although it is encouraging that children's expectancy-beliefs and physical activity did not significantly decrease across one academic year, it remains a concern that task value beliefs significantly decreased as early as $4^{\text {th }}$ grade. Furthermore, those individuals may be more likely to be physically inactive after getting into the middle school with decreased task value motivation and intention to participate in their current physical education program.

Taken together, the pattern of relationships among expectancy-related beliefs, task values, physical activity, and intention for future participation supports theoretical predictions and provides evidence that promoting physical education motivation in middle childhood has the potential to produce sustainable intention for future participation and long term physical activity maintenance. Middle childhood seems as an important period to build children's self-perceptions (e.g., competence beliefs, task values) and the behavioral habits (e.g., physical activity participation). Thus, school physical education must devote special efforts to foster physical and psychosocial development of all children as early as possible. Based on previous research evidence, health promoters and researchers need to focus on the development and implementation of physical activity motivational programs that incorporate both optimum expectancy-related beliefs and subjective task values, and reinforce the value of positive activity outcomes such as increased participation and intention related to physical activity (Gu \& Solmon, 2016; Solmon, 2015).

There is a broad agreement, however, that effective public health approaches to promoting school-aged children's physical activity should emphasize the role of physical education environment (e.g., competence support) as a key modifiable determinant of physical activity (Gu \& Solmon, 2016; Zhang et al., 2012). Physical activity participation is a motivated behavior, in that a student ultimately must decide whether or not to actually engage in that behavior. As noted by Wigfield and Eccles there is an important decision-making component to motivation. Indeed, individuals make different types of decisions depending on the perceived contextual information that is presented to them. Thus, one of the logical implications of the research on school-aged children's physical activity is that physical education teachers and other professionals can affect students' decision-making process. Consequently, they must make every effort to create a positive climate that will foster and maintain adaptive physical education motivation. Other socializing agents beyond the class content, such as teachers, parents and siblings' behaviors or perceptions are likely to be instrumental in shaping children's expectancyrelated beliefs and task values at this age.

\section{Conclusion}

Future studies should address the influence of the socializing agents and varied sources of expectancy-related beliefs and task values in addressing changes (i.e., decreases) of children's expectancy beliefs and values within or beyond physical education setting in the entire childhood (earlier, middle and later childhood).

\section{References}

Caspersen, C. J., Pereira, M. A., \& Curran, K. M. (2000). Changes in Physical Activity Patterns in the United States, by Sex and Cross-Sectional Age. Medicine and Science in Sports and Exercise, 32, 1601-1609.

http://dx.doi.org/10.1097/00005768-200009000-00013

Chen, A. (2015). Operationalizing Physical Literacy for Learners: Embodying the Motivation to Move. Journal of Sport and Health Science, 4, 125-131. http://dx.doi.org/10.1016/j.jshs.2015.03.005

Cox, A. E., Smith, A. L., \& Williams, L. (2008). Change in Physical Education Motivation and Physical Activity Behavior 
during Middle School. Journal of Adolescent Health, 43, 506-513. http://dx.doi.org/10.1016/j.jadohealth.2008.04.020

Eccles, J. S., \& Harold, R. D. (1991). Gender Differences in Sport Involvement: Applying the Eccles’ Expectancy-Value Model. Journal of Applied Sport Psychology, 3, 7-35. http://dx.doi.org/10.1080/10413209108406432

Eccles, J. S., Adler, T. F., Futterman, R., Goff, S. B., Kaczala, C. M., Meece, J., \& Midgley, C. (1983). Expectancies, Values and Academic Behaviors. In J. T. Spence (Ed.), Achievement and Achievement Motives (pp. 75-146). San Francisco: W. H. Freeman.

Eccles, J. S., Wigfield, A., \& Schiefele, U. (1998). Motivation to Succeed. In W. Damon (Series Ed.) \& N. Eisenberg (Vol. Ed.), Handbook of Child Psychology: Vol. 3. Social, Emotional, and Personality Development (5th ed., pp. 1017-1095). New York: Wiley.

Eccles, J., Wigfield, A., Harold, R. D., \& Blumenfeld, P. (1993). Age and Gender Differences in Children's Self- and Task Perceptions during Elementary School. Child Development, 64, 830-847. http://dx.doi.org/10.2307/1131221

Fredricks, J. A., \& Eccles, J. S. (2002). Children’s Competence and Value Beliefs from Childhood through Adolescence: Growth Trajectories in Two Male-Sex-Types Domains. Developmental Psychology, 38, 519-533.

http://dx.doi.org/10.1037/0012-1649.38.4.519

Gao, Z., Lee, A. M., \& Harrison, L. (2008). Understanding Students’ Motivation in Sport and Physical Education: From the Expectancy-Value Model and Self-Efficacy Theory Perspectives. Quest, 60, 236-254. http://dx.doi.org/10.1080/00336297.2008.10483579

Gao, Z., Lee, A. M., Solmon, M. A., \& Zhang, T. (2009). Changes in Middle School Students' Motivation toward Physical Education over One School Year. Journal of Teaching in Physical Education, 28, 378-399.

Gu, X., \& Solmon, M. (2016). Motivational Processes in Children’s Physical Activity and Health-Related Quality of Life. Physical Education and Sport Pedagogy, 21, 407-424. http://dx.doi.org/10.1080/17408989.2015.1017456

Jacobs, J. E., Lanza, S., Osgood, D. W., Eccles, J. S., \& Wigfield, A. (2002). Changes in Children’s Self-Competence and Values: Gender and Domain Differences across Grade One through Twelve. Child Development, 73, 509-527. http://dx.doi.org/10.1111/1467-8624.00421

Kowalski, K. C., Crocker, P. R. E., \& Faulkner, R. A. (1997). Validation of the Physical Activity Questionnaire for Older Children. Pediatric Exercise Science, 9, 174-186.

SHAPE America (2014). National Standards \& Grade-Level Outcomes for K-12 Physical Education. Champaign, IL: Human Kinetics.

Solmon, M. A. (2015). Optimizing the Role of Physical Education in Promoting Physical Activity: A Social-Ecological Approach. Research Quarterly for Exercise and Sport, 86, 329-337. http://dx.doi.org/10.1080/02701367.2015.1091712

USDepartment of Health and Human Services (2010). Healthy People 2020. http://www.healthypeople.gov/2020/

Wigfield, A., \& Eccles, J. S. (2002). The Development of Competence Beliefs, Expectancies for Success and Achievement Values from Childhood through Adolescence. In A. Wigfield, \& J. S. Eccles (Eds.), Development of Achievement Motivation (pp. 91-120). London: Academic Press. http://dx.doi.org/10.1016/B978-012750053-9/50006-1

Wigfield, A., Eccles, J. S., Yoon, K. S., Harold, R. D., Arbreton, A. J., Freedman-Doan, C., \& Blumenfeld, P. C. (1997). Change in Children's Competence Beliefs and Subjective Task Values across the Elementary School Years: A 3-Year Study. Journal of Educational Psychology, 89, 451-469. http://dx.doi.org/10.1037/0022-0663.89.3.451

Xiang, P., McBride, R. E., \& Bruene, A. (2006). Fourth-Grade Students’ Motivational Changes in an Elementary Physical Education Running Program. Research Quarterly for Exercise and Sport, 77, 195-207. http://dx.doi.org/10.1080/02701367.2006.10599354

Xiang, P., McBride, R., Guan, J., \& Solmon, M. A. (2003). Children's Motivation in Elementary Physical Education: An Expectancy-Value Model of Achievement Choice. Research Quarterly for Exercise and Sport, 74, 509-527. http://dx.doi.org/10.1080/02701367.2003.10609061

Zhang, T., Solmon, M. A., \& Gu, X. (2012). The Role of Teachers' Support in Predicting Students' Motivation and Achievement Outcomes in Physical Education. Journal of Teaching in Physical Education, 31, 329-343. 


\section{Submit or recommend next manuscript to SCIRP and we will provide best service for you:}

Accepting pre-submission inquiries through Email, Facebook, LinkedIn, Twitter, etc.

A wide selection of journals (inclusive of 9 subjects, more than 200 journals)

Providing 24-hour high-quality service

User-friendly online submission system

Fair and swift peer-review system

Efficient typesetting and proofreading procedure

Display of the result of downloads and visits, as well as the number of cited articles

Maximum dissemination of your research work

Submit your manuscript at: http://papersubmission.scirp.org/ 